\title{
Epidemiology, Nasopharyngeal Carriage, Serotype Prevalence, and Antibiotic Resistance of Streptococcus pneumoniae in Indonesia
}

\author{
Cissy B. Kartasasmita - Sri Rezeki Hadinegoro - Nia Kurniati • \\ Rina Triasih · Carolina Halim · Amgad Gamil
}

Received: May 7, 2020 / Published online: August 30, 2020

(C) The Author(s) 2020

\begin{abstract}
In Indonesia, pneumococcal disease represents a considerable public health concern; however, published data on the epidemiology, nasopharyngeal carriage, serotype prevalence, and antibiotic resistance of Streptococcus pneumoniae in this region are limited. Therefore, this article reviews the available data from a variety of sources and also summarizes pneumococcal conjugate vaccine implementation and recommendations in Indonesia and subsequent
\end{abstract}

Digital Features To view digital features for this article go to https://doi.org/10.6084/m9.figshare.12801068.

C. B. Kartasasmita

Department of Child Health, Universitas

Padjadjaran/Hasan Sadikin General Hospital,

West Java, Indonesia

S. Rezeki Hadinegoro · N. Kurniati

Department of Child Health, Faculty of Medicine, Universitas Indonesia-Dr. Cipto Mangunkusumo

Hospital, Jakarta, Indonesia

R. Triasih

Department of Child Health, Faculty of Medicine, Public Health and Nursing, Universitas Gadjah

Mada/Dr. Sardjito Hospital, Yogyakarta, Indonesia

C. Halim

Pfizer Indonesia, Jakarta, Indonesia

A. Gamil $(\bowtie)$

Pfizer Inc, Emerging Markets, Medical and Scientific

Affairs, Dubai, UAE

e-mail: Amgad.Gamil@pfizer.com impact on pneumococcal disease. Regional pneumococcal vaccination recommendations in Asia were also reviewed. Studies showed that pneumococcal nasopharyngeal carriage prevalence in Indonesia was approximately $43 \%$ to $55 \%$ in healthy children aged less than 5 years, which varied by age group, region, and year. Serotype analysis of pneumococcal nasopharyngeal carriage isolates in Indonesia revealed that $38 \%$ to $60 \%$ of isolates would be covered by the 13-valent pneumococcal conjugate vaccine (PCV13). The antimicrobial resistance of pneumococcal disease has increased over time; between 1997 and 2012, resistance to penicillin and sulfamethoxazole increased from $0 \%$ to $28 \%$ and $9 \%$ to $62 \%$, respectively. Inclusion of pneumococcal conjugate vaccines into immunization programs is being implemented gradually. In 2017, Indonesia implemented a regional PCV13 immunization program in Lombok with a $2+1$ vaccination schedule that was expanded in 2018-2019 to West Nusa Tenggara and Bangka Belitung Provinces; this expansion is predicted to substantially reduce the burden of pneumococcal disease in Indonesia. Overall, the limited data available regarding pneumococcal disease in Indonesia highlight the unmet need for comprehensive disease surveillance studies in this region that can help direct vaccination strategies. 
Keywords: Antibiotic resistance; Indonesia; Nasopharyngeal carriage; Pneumococcal disease; Pneumococcal vaccination

\section{Key Summary Points}

Pneumococcal disease (PD) causes a substantial health burden in Indonesia.

Pneumococcal nasopharyngeal carriage prevalence is approximately $43 \%-55 \%$ in healthy Indonesian children aged less than 5 years.

Serotype analysis of pneumococcal nasopharyngeal carriage isolates revealed that $38 \%-60 \%$ of isolates would be covered by the 13 -valent pneumococcal conjugate vaccine.

Vaccination is vital to decrease antibiotic resistance, which has been shown in PD.

Vaccination with pneumococcal conjugate vaccines was introduced in Indonesia as a regional immunization program in 2017 with the goal of reducing the incidence of PD in children.

\section{INTRODUCTION}

Streptococcus pneumoniae is a leading cause of invasive bacterial diseases, such as bacteremic pneumonia, meningitis, and sepsis, and poses a significant health concern in industrialized and nonindustrialized countries [1]. Globally, pneumococcal diseases are estimated to cause $11 \%$ of all deaths among children aged 1 to 59 months who are HIV-negative; this estimate is likely to be lower than the true mortality owing to an overestimation of deaths averted by vaccine introduction [2]. Pneumococcal pneumonia is estimated to represent more than $95 \%$ of all pneumococcal disease cases and estimated to have occurred in 8.9 million children worldwide in 2015. Case fatality rates (CFRs) due to pneumococcal pneumonia range from $1 \%$ to
$6 \%$ depending on the region, with Southeast Asia having the highest numbers of patients affected [2]. Globally, an estimated 83,900 cases of pneumococcal meningitis and 326,000 cases of invasive non-pneumonia, non-meningitis (i.e., sepsis and other invasive pneumococcal diseases, IPDs) occurred between 2000 and 2015 [2].

Bacterial colonization of the nasopharynx precedes pneumococcal disease, an event that typically occurs in the absence of any discernible symptoms $[1,3]$. Once bacteria are established in the nasopharynx, they can be transmitted by aerosolized droplets and colonized in a new host. The bacteria can also traverse the mucosal barrier to cause acute otitis media and/or enter the bloodstream, leading to IPD $[1,3]$. Thus, nasopharyngeal carriage (NPC) prevalence data are also important considerations in controlling pneumococcal disease in the community.

Currently, more than 90 pneumococcal serotypes are identified, and a subset of these are associated with most IPD cases worldwide [1]. Pneumococcal conjugate vaccines (PCVs) targeting 7,10 , or 13 of these serotypes and a nonconjugate pneumococcal polysaccharide vaccine targeting 23 serotypes have been effective in reducing IPD incidence; accordingly, the prevalence and distribution of disease-causing serotypes have changed over time [4]. Due largely to vaccination, estimated IPD-associated deaths in children aged less than 5 years decreased globally from 735,000 in 2000 to 294,000 in 2015 [2]. Although this represents a $51 \%$ decline in deaths among children between 2000 and 2015, less conservative estimates report as many as 515,000 deaths in 2015 [2]. Thus, a significant pneumococcal disease burden remains, particularly in developing countries, and PCVs are important to reduce pneumococcal disease-associated deaths [1]. Identifying specific serotypes responsible for pneumococcal disease in different regions is a public health priority and requires continued surveillance [4].

Indonesia accounts for a substantial disease burden within Asia and is estimated to represent 3\% of global pneumococcal disease cases [5]. However, there are limited published data of 
pneumococcal disease in Indonesia. Thus, this review summarizes available data on pneumococcal disease epidemiology, NPC, serotype prevalence, antibiotic resistance, and vaccine coverage in Indonesia, as well as considering regional pneumococcal vaccination recommendations in Asia. The available studies on pneumococcal disease burden were also briefly reviewed and highlight the unmet need for comprehensive disease surveillance studies in Indonesia that can help direct successful pneumococcal vaccine strategies.

\section{METHODS}

A literature search for this narrative review was performed using PubMed. Search terms of (pneumoco*) AND (Indonesia) AND (epidemiology OR burden OR carriage OR colonization OR antibiotic resistance OR AMR OR vaccination OR immunization) and limited for Englishlanguage articles published after January 1, 2000 , were used. This search strategy retrieved 31 articles out of which 13 were relevant to the topics covered in this review. When necessary, references cited in the retrieved publications were used; authors and/or experts in the field were also contacted as needed. In addition, references from the authors' personal files and data from the Ministry of Health Indonesia and other regulatory agencies when topically relevant and helpful for discussion were reviewed. This article is based on previously conducted studies and does not contain any studies with human participants or animals performed by any of the authors.

\section{BURDEN OF PNEUMOCOCCAL DISEASES IN INDONESIA}

Indonesia currently does not conduct routine surveillance for bacterial respiratory diseases [6] and as such the overall incidence of pneumococcal disease in Indonesia has not been reported. Estimates of pneumococcal disease have relied on studies examining the disease burden among Indonesian children. Modeling studies suggest a significant pneumococcal disease burden in Indonesia. For example, a systematic review using an epidemiological model estimated that of $21,578,876$ children aged 0 to 4 years in Indonesia, 3,918,360 $(18.2 \%)$ suffered from pneumonia in 2010, $14.3 \%$ of which was caused by S. pneumoniae [7]. This was the third highest number of pneumonia cases among Southeast Asian countries. Death due to pneumonia was estimated in 6311 children, corresponding to a CFR of $2.3 \%$ in this population. A recent study of annual-modeled country-specific estimates reported 585,770 cases of pneumococcal pneumonia in Indonesian children aged 1 to 59 months and 7221 pneumonia deaths, 796 meningitis deaths, and 708 non-pneumonia, non-meningitis deaths due to $S$. pneumoniae in 2015 [2].

A 2008-2009 hospital-based surveillance study among children aged 28 days to less than 60 months in Surabaya and Bandung estimated the percentage of IPD cases as $0.5 \%(5 / 1040)$ and $0.4 \%(2 / 466)$, respectively) $[8,9]$. The serotypes causing IPD were $14,23 \mathrm{~F}$, and 5 in Surabaya and 14 and 23F in Bandung $[8,9]$. In a small prospective study in two academic referral hospitals in Jakarta, of the 205 patients hospitalized with pneumonia, meningitis, sepsis, or suspected occult bacteremia, 1 (0.5\%) had blood-culture-positive $S$. pneumoniae serotype 7F [10]. However, it is important to note that preculture antibiotic use and/or the significant presence of contaminant organisms in study specimens may have affected the IPD burden reported within these studies [8-10]. Further, these hospital-based studies are geographically limited and thus might not fully represent the nationwide pneumococcal disease burden in Indonesian children.

All-cause pneumonia is a leading cause of death in children in Indonesia [11], with the country ranking the sixth highest globally for new childhood pneumonia cases per year and approximately 6 million new cases predicted annually [12]. All-cause pneumonia is common among Indonesian children and was estimated to occur in 505,331 children aged less than 5 years in 2018 [13]. The reported nationwide CFR in children aged less than 5 years was $0.08 \%$ in 2018 , with rates as low as 0\% in Jambi, South Sumatera, Riau, DKI Jakarta (Special 
Capital City Region), Central Kalimantan, Southeast Sulawesi, Maluku, and Papua and as high as $4.73 \%$ in West Kalimantan. However, it should be noted that the availability of surveillance data varied greatly across provinces and was considerably low in some provinces [13]. The United Nations Children's Fund (UNICEF) reported in 2015 that approximately 25,000 deaths among Indonesian children aged less than 5 years could be attributed to all-cause pneumonia [14]. In a study that derived pneumonia incidence rates for the 2007 Indonesian birth cohort from a randomized vaccine probe study conducted in Lombok, it was estimated that of 4.2 million children, pneumonia would develop in 5,674,350 children and cause 103,407 deaths during the first 5 years of life without vaccination [15]. A retrospective study from 2010 to 2011 identified 949 suspected pneumonia cases in hospitalized children aged less than 5 years in the city of Bandung, accounting for $18.0 \%$ of all hospitalizations for that age group [16]. More recently, a 2019 systematic analysis indicated pneumonia incidence in Indonesian children aged less than 5 years had decreased between 2000 and 2015, from 487 per 1000 population to 326 per 1000 population [17]. Data for other age groups are more limited, but one study estimated that the 2010 rate of all-cause pneumonia diagnosed among Indonesian hospitalized patients of any age was $1.5 \%$ [18]. However, it should be noted that stakeholders estimated that an overall pneumonia incidence rate of $10 \%$ (rather than the reported $1.5 \%$ ) more closely reflected their clinical experience [18].

\section{Prevalence of Nasopharyngeal Carriage in Indonesia}

Several studies among healthy Indonesian children reported a consistently high NPC prevalence despite variation in regions and dates (Table 1). The most recent study in this population, conducted in 2017 in children aged less than 5 years, reported NPC rates of $55 \%$, ranging from $31.2 \%$ in Gunungkidul to $84.5 \%$ in Southwest Sumba, with the differences thought to be attributed to variability in characteristics in the two populations [6]. In a 2012 study in Central Lombok Regency of 1200 children aged 2 to 60 months, variation in NPC prevalence was observed among villages, ranging from $39 \%$ to $52 \%$ [19]. Another study in West Java reported higher prevalence of NPC in rural compared with urban communities (49.3\% vs 36.9\%). A 2016 study in children aged 1 to 2 years also documented provincial variation, reporting rates ranging from approximately $35 \%$ in the city of Padang to $64 \%$ in the city of Bandung [20].

NPC prevalence in Indonesia also varied by age group. A study from Lombok reported that NPC prevalence was significantly higher among children aged 24 months or younger (53\%) compared with other age groups (aged 25-48 months, 39\%; aged 49-72 months, 37\%; $P=0.001$ ) [19]. A study published in 2006 tracked 108 newborns in Bandung to determine changes in NPC prevalence over time. One positive pneumococcal isolate was detected in newborns within 6 to $12 \mathrm{~h}$ of birth, but 15 isolates (13.9\% of infants) were identified 8 weeks later [21]. The most common suggested source of transmission identified was older siblings, with $57 \%$ of infants aged 2 months or younger who tested positive for NPC having an older sibling who was also positive for NPC. Another prospective study followed 200 Indonesian infants over their first year of life; NPC prevalence increased from $22.0 \%$ in those aged 8 to 12 weeks to $68.4 \%$ in those aged 1 year [22]. Studies in adults reported positive NPC in 11\% of those aged 45 to 70 years in Semarang [23] and 3\% of those aged 60 to 97 years in Jakarta [24]. Additionally, one study examined NPC in Indonesian children with HIV (Table 1) [25].

\section{AVAILABLE VACCINES, SEROTYPE DISTRIBUTION, AND ESTIMATED VACCINE COVERAGE}

In Indonesia, three vaccines are available to prevent pneumococcal disease, including the 23-valent pneumococcal polysaccharide vaccine (PPSV23) and the 10- or 13-valent PCVs (PCV10 [also known as PHiD-CV] and PCV13) $[1,26,27]$. PCV10 and PCV13 consist of 
Table 1 Pneumococcal nasopharyngeal carriage rates in Indonesia

\begin{tabular}{|c|c|c|c|c|c|c|c|}
\hline $\begin{array}{l}\text { HIV } \\
\text { status }\end{array}$ & Age & $\begin{array}{l}\text { Period of } \\
\text { study }\end{array}$ & Region & Setting & $\begin{array}{l}\text { Number of } \\
\text { specimens } \\
\text { collected }\end{array}$ & $\begin{array}{l}\text { NPC } \\
\text { prevalence, } \\
\%\end{array}$ & Reference \\
\hline \multirow[t]{12}{*}{$\begin{array}{l}\text { HIV- } \\
\text { negative }\end{array}$} & $\begin{array}{l}0-6 \\
\text { months }\end{array}$ & 1997 & Lombok & $\begin{array}{l}\text { Community } \\
\text { survey }\end{array}$ & 159 & 41 & $\begin{array}{l}\text { Soewignjo } \\
\text { et al. [31] }\end{array}$ \\
\hline & $\begin{array}{l}0-24 \\
\text { months }\end{array}$ & 1997 & Lombok & $\begin{array}{l}\text { Community } \\
\text { survey }\end{array}$ & 484 & 48 & $\begin{array}{l}\text { Soewignjo } \\
\text { et al. [31] }\end{array}$ \\
\hline & $\begin{array}{l}0-2 \\
\text { months }\end{array}$ & 2004 & Bandung & $\begin{array}{l}\text { Community } \\
\text { survey }\end{array}$ & 108 & 13.9 & $\begin{array}{c}\text { Kartasasmita } \\
\text { et al. [21] }\end{array}$ \\
\hline & $\begin{array}{l}\text { 6-60 } \\
\text { months }\end{array}$ & 2010 & Semarang & $\begin{array}{l}\text { Community } \\
\text { survey }\end{array}$ & 243 & 43 & $\begin{array}{l}\text { Farida et al. } \\
\text { [23] }\end{array}$ \\
\hline & $\begin{array}{l}2-60 \\
\text { months }\end{array}$ & 2012 & Lombok & $\begin{array}{l}\text { Community } \\
\text { survey }\end{array}$ & 1200 & 46 & $\begin{array}{r}\text { Hadinegoro } \\
\text { et al. [19] }\end{array}$ \\
\hline & $\begin{array}{l}2-3 \\
\text { months }\end{array}$ & $2014-2015$ & Bandung & $\begin{array}{l}\text { Community } \\
\text { survey }\end{array}$ & $200^{\mathrm{a}}$ & 22 & $\begin{array}{l}\text { Murad et al. } \\
\text { [22] }\end{array}$ \\
\hline & $\begin{array}{l}12 \\
\text { months }\end{array}$ & $2014-2015$ & Bandung & $\begin{array}{l}\text { Community } \\
\text { survey }\end{array}$ & $200^{\mathrm{a}}$ & 68 & $\begin{array}{l}\text { Murad et al. } \\
\text { [22] }\end{array}$ \\
\hline & $1-2$ years & 2016 & Bandung & $\begin{array}{l}\text { Community } \\
\text { survey }\end{array}$ & 100 & $64^{b}$ & $\begin{array}{l}\text { Dunne et al. } \\
\text { [20] }\end{array}$ \\
\hline & $1-2$ years & 2016 & Padang & $\begin{array}{l}\text { Community } \\
\text { survey }\end{array}$ & 101 & $35^{b}$ & $\begin{array}{l}\text { Dunne et al. } \\
{[20]}\end{array}$ \\
\hline & $1-2$ years & 2016 & Lombok & $\begin{array}{l}\text { Community } \\
\text { survey }\end{array}$ & 101 & $50^{\mathrm{b}}$ & $\begin{array}{l}\text { Dunne et al. } \\
{[20]}\end{array}$ \\
\hline & $0-5$ years & 2017 & Gunungkidul & $\begin{array}{l}\text { Community } \\
\text { survey }\end{array}$ & 1008 & 31.2 & $\begin{array}{l}\text { Safari et al. } \\
{[6]}\end{array}$ \\
\hline & $0-5$ years & 2017 & $\begin{array}{c}\text { Southwest } \\
\text { Sumba }\end{array}$ & $\begin{array}{l}\text { Community } \\
\text { survey }\end{array}$ & 814 & 84 & $\begin{array}{l}\text { Safari et al. } \\
{[6]}\end{array}$ \\
\hline $\begin{array}{l}\text { HIV- } \\
\text { positive }\end{array}$ & $\begin{array}{l}\text { 4-144 } \\
\text { months }\end{array}$ & 2012 & Jakarta & $\begin{array}{l}\text { Outpatient } \\
\text { hospital visit }\end{array}$ & 90 & 46 & $\begin{array}{l}\text { Safari et al. } \\
{[25]}\end{array}$ \\
\hline
\end{tabular}

NPC nasopharyngeal carriage

${ }^{a}$ Number of specimens collected per age group not provided; specimen number is for total samples collected from children aged 2-12 months

$\mathrm{b}$ Estimated value

serotypes $1,4,5,6 \mathrm{~B}, 7 \mathrm{~F}, 9 \mathrm{~V}, 14,18 \mathrm{C}, 19 \mathrm{~F}$, and 23F [1]. PCV13 also consists of serotypes 3, 6A, and 19A [1]. PPSV23 includes the same serotypes as PCV10 and PCV13 (except for 6A) as well as serotypes $2,8,9 \mathrm{~N}, 10 \mathrm{~A}, 11 \mathrm{~A}, 12 \mathrm{~F}, 15 \mathrm{~B}$, 17F, 20, 22, and 33F [28]. PCV10 and PCV13 are indicated for infants and children aged 6 weeks through 5 years. PCV13 is also indicated up to those aged through 17 years and for adults $[29,30]$. In Indonesia, PCV13 is indicated for children aged 6 weeks through 5 years and for adults aged 50 years and older [27]. 
Determining the most common serotypes isolated from the population is of importance to better understand vaccine coverage and the potential for vaccination to reduce pneumococcal disease burden in Indonesia. NPC serotype data are relevant to estimate serotype distribution because carriage and invasive serotypes have been found to be similar [31]. In 1997, NPC isolates were detected in $48 \%$ of 221 children aged 25 months or younger in Lombok Island, of which $25 \%$ and $21 \%$ were serotypes 6 and 23, respectively [31]. Overall, $61 \%$ of the isolates were covered by serotypes contained in the 7-valent PCV (PCV7), which was in use at the time [31]. Similarly, serotype 6A/B was identified in 2012 as the most common serotype (22\%) among 554 NPC isolates of 1200 healthy children aged 2 to 60 months in Lombok Island. The other common serotypes were 19F (11\%), 23F (10\%), 15B/C (8\%), and 19A and $14 \mathrm{~A}(4 \%$ each) [19]. Overall serotype coverage by PCV13 was $56 \%$.

In a prospective study of infants aged 2 to 12 months in West Java, the most frequent serotypes in NPC isolates were 6B, NT2 (an acapsular pneumococci), 19F, 23F, 34, and 15B/C [22]. Serotypes 6A, 19A, and 3, which are covered by PCV13 but not PCV10, were also detected [32]. Results indicated that $38.4 \%$ of carriage episodes in this region were covered by PCV13. In Semarang, the most common NPC isolates among children aged 6 to 60 months were serotypes $6 \mathrm{~A} / \mathrm{B}, 15 \mathrm{~B} / \mathrm{C}, 11 \mathrm{~A}, 23 \mathrm{~F}, 19 \mathrm{~F}$, and 23A [23]. A more recent study conducted in 2016 among 302 children aged 1 to 2 years from Bandung, Lombok, and Padang identified $15 \mathrm{~B} / \mathrm{C}$ as the most common serotype among 164 NPC isolates, followed by 23F, NT2, 19F, and 6A; serotypes 19A and 3 were also detected. Overall, $46.3 \%$ of isolates were covered by PCV13, with regional variation in coverage from $36 \%$ in Bandung to 58\% in Padang, and $32.3 \%$ were covered by PCV10 [20].

Serotype distribution in healthy adults was reported in two NPC studies [23, 24]. One study identified four serotypes $(3,6 \mathrm{~A} / \mathrm{B}, 15 \mathrm{~B} / \mathrm{C}, 35 \mathrm{~F})$ among 16 NPC isolates collected from 149 adults aged 60 to 97 years in Jakarta [24]. Another study of 253 adults aged 45 to 70 years in Semarang reported that serotype 6A/B was most common (39\% of isolates) [23].

While some studies suggest that serotypes $6 \mathrm{~A} / \mathrm{B}$ and $15 \mathrm{~B} / \mathrm{C}$ are the most common NPC serotypes among HIV-negative children $[19,20,22,23]$, serotype $19 \mathrm{~F}$ (followed by 19A and $16 \mathrm{~A} / \mathrm{B}$ ) was reported as the most frequent serotype in 90 HIV-positive children aged 4 to 144 months in Jakarta [25]. The majority of isolates $(60 \%)$ were covered by PCV13. Nevertheless, it is difficult to determine whether this difference is because of the HIV infection or because of regional or temporal variation. In adults, the most common serotype identified among NPC isolates from 20 HIV-infected adults carrying S.pneumoniae was 6A/B [33], consistent with findings in children $[19,22,23]$ and adults who are HIV-negative [23].

\section{ANTIBIOTIC RESISTANCE IN INDONESIA}

The highest rates of antibiotic resistance worldwide have been consistently reported in Asia [34], and a surveillance study conducted by the Asian Network for Surveillance of Resistant Pathogens from 2008/2009 suggested that the number of resistant strains may be increasing [35]. Specifically in this study, macrolide resistance was more common than previously observed in Asia and compared with rates reported in Western countries. The prevalence of multidrug resistance was 59.3\%. Many pneumococcal serotypes have been reported as being resistant to commonly used antibiotics, including penicillins, macrolides, cephalosporins, and co-trimoxazole [1]. Certain serotypes in particular (i.e., 6B, 9V, 14, 19A, 19F, 23F) are most likely to be associated with antibiotic resistance [1].

Several studies investigating NPC and serotype distribution in Indonesia reported decreased susceptibility to common antibiotics. In a 1997 study of NPC among Indonesian children in Lombok, $12 \%$ of isolates were resistant to at least one of the four antibiotics tested, but none were resistant to all [32]. All strains were susceptible to penicillin, and 91\% were susceptible to sulfamethoxazole. In an 
NPC study conducted 15 years later among children in Lombok, only $72 \%$ of isolated strains were still susceptible to penicillin and $38 \%$ were susceptible to sulfamethoxazole/ trimethoprim [19]. An NPC study in Semarang identified high levels of antibiotic resistance among children and adults, with $24 \%$ of strains resistant to penicillin and $45 \%$ of strains resistant to sulfamethoxazole/trimethoprim [23]. Hence, guidelines now recommend oral administration of amoxicillin for mild pneumonia in children, replacing the previously commonly used sulfamethoxazole/trimethoprim $[36,37]$.

Antibiotic resistance rates were even higher in two studies of individuals with HIV living in Jakarta. In children with HIV, 67\%, 59\%, and $38 \%$ of the isolated strains were resistant to penicillin, sulfamethoxazole/trimethoprim, or multiple drugs, respectively [25]. In adults with $\mathrm{HIV}$, corresponding percentages were $45 \%$, $85 \%$, and $45 \%$, respectively [33].

\section{IMPACT OF PNEUMOCOCCAL VACCINATION IN ASIA}

Worldwide, substantial progress has been made in increasing PCV vaccination coverage in children. In 2020, 159 countries had introduced a PCV in their national immunization program (NIP), including 60 Global Alliance for Vaccines and Immunizations (Gavi) countries; 15 plan to introduce PCVs in their NIP, 120 have introduced PCV13, 32 have introduced PCV10, and 7 have introduced both vaccines in their programs [38]. Many Asian countries (e.g., Cambodia, Philippines, Taiwan, Singapore, India) have recently introduced PCVs into their routine NIP [39-44]. The schedule of PCVs varies by country (e.g., a two- or three-dose primary series followed by a 12-month booster, a three-dose primary series at ages 6,10 , and 14 weeks) [45]. In Indonesia, PCVs have been recommended in the private sector by the Indonesian Pediatric Society (IPS) since 2006, with suggested scheduled doses at ages 2, 4, and 6 months followed by a booster at 12 to 15 months of age $[46,47]$. The schedule used in the regional immunization program in Lombok included a two-dose primary series at 2 and 3 months of age followed by a 12 -month booster [48].

An estimated $47 \%$ of the world's infants (64.1 million) are receiving PCV, according to 2017 WHO/UNICEF estimates of national immunization coverage [38]. In 2018, in certain Asian countries which have recently introduced PCVs into their NIP, the PCV coverage rate (three-dose) was 93\% in Cambodia, $82 \%$ in Singapore, $60 \%$ in Philippines, and $44 \%$ in India [49]. In contrast, in 2019, the PCV coverage rate for the same three-dose schedule in Indonesia was only 8\% [50]; this low coverage rate is likely because PCV vaccines are only administered in private settings and the regional vaccination program was only initiated recently [51].

\section{Pneumococcal Vaccination in Indonesia: Practices and Barriers}

Indonesia's geography (an archipelago with more than 16,000 islands) and large birth cohort present challenges for implementing immunization programs [13]. Despite these challenges, the NIP intends for each infant to receive complete basic immunization, with a 2018 Strategic Plan target of 92.5\% [13]. Strong efforts have been made to date, resulting in an achievement of $90.6 \%$, with as many as 13 out of 34 Indonesian provinces (38\%) reaching that target [13].

The WHO has stated that PCVs are efficacious, well tolerated, and cost-effective and should be included in all childhood immunization programs worldwide [1]. Further, a recent study indicated that implementing a national PCV immunization plan in Indonesia would be highly cost-effective [52]. Currently, good progress has been made with introducing PCVs as a regional immunization program, beginning with PCV13 in East and West Lombok districts of West Nusa Tenggara Province in 2017 [48, 51]. PCVs were expanded to Bangka Belitung Province in 2018-2019 and the remaining districts of West Nusa Tenggara Province in 2019 [51, 53].

Barriers to PCV vaccination remain substantial, with a concern being limited international 
funding available to cover national implementation [54]. Amid other nationwide health reforms related to financial responsibility for the NIP, Indonesia may face several logistical challenges, including delivery of vaccines and coordination of immunization programs, and a large financial burden as new vaccines are introduced in the coming years [55]. In addition, a qualitative study conducted in 2011 on knowledge, perceptions, and attitudes of Indonesian mothers and healthcare providers toward PCVs showed that both populations had limited knowledge about PCVs [56]. Therefore, increasing awareness about pneumococcal disease and its prevention also needs to be addressed.

Indonesia currently lacks a national surveillance program to assess the true burden of bacterial respiratory illnesses in the country [6]. As such the implementation of a PCV program in Indonesia may be hampered by the lack of country-wide estimates of pneumococcal disease [23]. Such barriers could potentially be overcome through national surveillance efforts-both for the detection of S. pneumoniae and determination of serotype distribution in the country. Strengthening infrastructure for laboratory-based diagnostic methods for the detection of S. pneumoniae including culturebased detection methods, urine antigen detection, and polymerase chain reaction (PCR)based assays remain crucial to this goal [57]. Further, rapid, sensitive, and cost-effective methods are needed to understand the true serotype distribution of S. pneumoniae in countries such as Indonesia [58]. Recently, a novel technique called loop-mediated isothermal amplification (LAMP) has been developed for the serotype-specific identification of S. pneumoniae and was found to be as sensitive as traditional PCR-based assays in its ability to detect and identify up to 55 different $S$. pneumoniae serotypes [58]. Importantly, in contrast to PCRbased assays, the LAMP technique does not require specialized equipment [58]. This costeffective methodology could be easily deployed by Indonesian authorities to both rural and urban areas of the country and thus could improve estimates of pneumococcal disease burden in the region [58]. In turn, accurate estimates of pneumococcal disease would allow governmental authorities to make more informed decisions regarding PCV implementation in Indonesia.

\section{Lessons Learned from Other Countries in Asia}

Studies in other Asian countries have indicated that PCV introduction to the NIP led to reduction in IPD incidence. For example, a study conducted in a hospital in Siem Reap, Cambodia, before the introduction of PCV13, showed that colonization of PCV13 serotypes accounted for $62.7 \%$ of NPC isolates from outpatients and $88.4 \%$ of IPD isolates [59]. In the year following PCV13 introduction, when PCV13 coverage was $66 \%$ in children aged less than 1 year living in Siem Reap, PCV13 serotype colonization decreased from $57.6 \%$ to $41.5 \% \quad(P=0.0001)$ [40]. A study in Mongolia showed that 1 year after the introduction of PCV13 in 2016, vaccine serotype carriage in children (aged 12-23 months) and unvaccinated infants (aged 5-8 weeks) decreased by $52 \%$ and $51 \%$, respectively [60]. Prior to vaccine introduction, PCV13 serotypes made up $70 \%$ and $45 \%$ of all pneumococci tested in children and infants, respectively. Of note, PCV13 coverage was $84 \%$ and $0 \%$ for Mongolian children and infants surveyed in the study. Similarly, a study in the Lao People's Democratic Republic showed that PCV13 serotype carriage prevalence 2 years after PCV inclusion in the NIP was significantly reduced in surveyed children (aged 12-23 months) [61]. Vaccine coverage was $90 \%$ for the children. However, pneumococcal carriage prevalence of PCV13 serotypes did not significantly change for unvaccinated infants (aged 5-8 weeks). For children and infants, PCV13 serotypes comprised $55 \%$ and $45 \%$, respectively, of all pneumococci tested prior to vaccine introduction.

In the Philippines, a study conducted between 2007 and 2009 reported that the incidence of IPD in children aged 28 days to less than 5 years was between 25.38 and 33.49 cases per 100,000 individuals [62]. Subsequently, in 2013, PCV10 was initially introduced as part of 
the government immunization program in the two regions with the highest pneumonia burden [39]. A year later, the government introduced PCV13 with a $3+0$ vaccination schedule in several other regions to cover the three additional serotypes present locally [39]. Laboratory-based surveillance of $S$. pneumoniae from 301 isolates collected across the country revealed that vaccine serotype coverage of PCV13 for the pediatric population was $71.2 \%$ [63]. A subsequent cost-utility analysis recommended that PCVs be included in the NIP and concluded that PCV13 would achieve better value than PCV10. However, the authors noted that decision makers need to consider the longterm affordability and sustainability of PCV implementation [64].

In India, $33.7 \%$ of mortality in those $1-59$ months of age is attributable to pneumonia [65]. A meta-analysis of four clinical studies showed that $30 \%$ to $40 \%$ of all severe pneumonia in Indian children is pneumococcal, and approximately 123,000 to 164,000 annual deaths in children aged less than 5 years are projected to be attributed to pneumococcal pneumonia [66]. As per modeling-based estimates conducted in 2010 in children aged less than 5 years, 560,000 severe pneumococcal pneumonia cases and 105,000 pneumococcal pneumonia deaths were estimated [67]. A 2009-2011 hospital-based surveillance study of children aged 28 days to less than 5 years reported the overall estimated incidence rate for IPD to be 17.8 cases per 100,000 children [68]. A systematic literature review documented the diverse serotypes of pneumococcus isolated from various parts of India; coverage of PCV10 was estimated to range from $61 \%$ to $68 \%$ and PCV13 from $74 \%$ to $92 \%$ [42]. In addition, currently available PCV formulations included $67.3 \%$ to $78.4 \%$ of all serotypes contributing to IPD among children aged 5 years or younger. Serotypes 14 and 19A were represented in most of the geographic regions studied in the reviewed articles. In 2017, India started a PCV13 immunization program with Gavi support in select states, representing $20 \%$ of the country's birth cohort; a $2+1$ vaccination schedule at age 6 weeks, 14 weeks, and 9 months is being used $[42,43,69]$.
In addition, several studies in Asian countries outside of Indonesia have shown that PCV can reduce antibiotic resistance rates. For example, PCV13 was gradually introduced in Taiwan beginning in 2011 and resulted in a 69\% reduction in IPD incidence between 2012 and 2017 in children aged 0 to 5 years [41, 70]. One study of pneumococcal isolates collected from children and adolescents at a large Taiwanese hospital during 2012 to 2016 showed that serotypes $19 \mathrm{~F}$ and $19 \mathrm{~A}$ had the highest penicillin non-susceptibility rates [71]. Antibiotic resistance rates of serotype $19 \mathrm{~F}$ significantly decreased between 2012 and 2014 (90.9\% to $61.5 \%$ ), but then increased to $100 \%$ in 2016 . However, rates for serotype 19A decreased following PCV13 introduction $(91.3 \%$ in 2012 to $69.2 \%$ in 2016). Similarly, a second study from the same hospital in Taiwan showed that the penicillin resistance rates in pediatric and adult pneumococcal isolates decreased following PCV13 introduction $(27.8 \%$ in 2012 to $8.1 \%$ in 2014) [41]. The highest penicillin resistant rates were observed for serotypes 19A and 19F, which decreased from $51.5 \%$ and $41.7 \%$ to $14.3 \%$ and $17.9 \%$, respectively, over the 2-year observation period. In Japan, PCV13 was first introduced in late 2013; a nationwide study analyzing pneumococcal disease from 2012 to 2014 in Japanese individuals aged 2 months to 16 years showed that the percentages of IPD isolates non-susceptible to penicillin and cefotaxime decreased during this study period [72].

Studies in other Asian countries have also indicated that wider implementation of a PCV immunization program may have a favorable cost benefit. A study in Bhutan showed that PCV13 introduction into the nationwide extended program would decrease healthcare costs by $13.6 \%$ over 5 years; the authors determined that the vaccine would not only be costeffective but also substantially reduce the workload for providers in Bhutan [73]. Overall, these studies suggest that widespread vaccination against pneumococcal disease, including PCV programs in Asia, may have demonstrable benefit for both costs and disease burden in Indonesia. 


\section{CONCLUSIONS}

Pneumococcal disease is a substantial public health burden in Indonesia; however, there is an overall lack of comprehensive surveillance data. Contemporary data and high quality disease surveillance are critical for better elucidating pneumococcal disease burden, serotype distribution, and antibiotic resistance among the Indonesian population to ensure their protection against pneumococcal disease. Pneumococcal-related studies have been conducted in different areas in the country as supporting scientific data for the rationale for PCV introduction. Overall, a national approach to disease surveillance and vaccination is needed to ensure that Indonesian children are fully protected from pneumococcal disease. Although Indonesia has not yet included PCVs in the NIP, progress has been made by initiating the vaccination as a regional program in selected provinces. This progress is a positive step towards reducing the incidence of pneumococcal disease in Indonesian children.

\section{ACKNOWLEDGEMENTS}

Funding. This work was sponsored by Pfizer Inc. Pfizer Inc funded the journal's Rapid Service Fees.

Medical Writing, Editorial, and Other Assistance. Editorial/medical writing support was provided by Emily Stackpole, PhD, Tricia Newell, PhD, and Srividya Ramachandran, PhD, of ICON plc (North Wales, PA, USA) and was funded by Pfizer Inc.

Authorship. All named authors meet the International Committee of Medical Journal Editors (ICMJE) criteria for authorship for this article, take responsibility for the integrity of the work as a whole, and have given their approval for this version to be published.

Disclosures. Amgad Gamil and Carolina Halim are employees of Pfizer Inc and Pfizer Indonesia, respectively, and may hold stock/stock options. Cissy B. Kartasasmita has received research support and has been a scientific consultant and speaker for Pfizer. Nia Kurniati has been a scientific consultant for Pfizer. Rina Triasih has been a speaker and an advisory board member for Pfizer. Sri Rezeki Hadinegoro has received research support and has been a scientific consultant and a speaker for Pfizer and Sanofi and a scientific consultant and a speaker for GSK and Merck.

Compliance with Ethics Guidelines. This article is based on previously conducted studies and does not contain any studies with human participants or animals performed by any of the authors.

Data Availability. Data sharing is not applicable to this article as no datasets were generated or analyzed during the current study.

Open Access. This article is licensed under a Creative Commons Attribution-NonCommercial 4.0 International License, which permits any non-commercial use, sharing, adaptation, distribution and reproduction in any medium or format, as long as you give appropriate credit to the original author(s) and the source, provide a link to the Creative Commons licence, and indicate if changes were made. The images or other third party material in this article are included in the article's Creative Commons licence, unless indicated otherwise in a credit line to the material. If material is not included in the article's Creative Commons licence and your intended use is not permitted by statutory regulation or exceeds the permitted use, you will need to obtain permission directly from the copyright holder. To view a copy of this licence, visit http://creativecommons.org/licenses/by$\mathrm{nc} / 4.0 /$.

\section{REFERENCES}

1. World Health Organization. Pneumococcal conjugate vaccines in infants and children under 5 years of age: WHO position paper-February 2019. https://apps.who.int/iris/bitstream/handle/10665/ 
310968/WER9408.pdf?ua=1. Accessed June 28, 2019.

2. Wahl B, O'Brien KL, Greenbaum A, et al. Burden of Streptococcus pneumoniae and Haemophilus influenzae type $b$ disease in children in the era of conjugate vaccines: global, regional, and national estimates for 2000-15. Lancet Glob Health. 2018;6: e744-e757.

3. Kartasasmita C, Roesmil K, Fadlyana E, et al. A longitudinal study of carriage of Streptococcus pneumoniae in Indonesian infants in the first year of life. Presented at International Symposium on Pneumococci and Pneumococcal Diseases, June 26-30, 2016; Glasgow, UK.

4. Balsells E, Guillot L, Nair H, Kyaw MH. Serotype distribution of Streptococcus pneumoniae causing invasive disease in children in the post-PCV era: a systematic review and meta-analysis. PLoS One. 2017;12:e0177113.

5. O'Brien KL, Wolfson LJ, Watt JP, et al. Burden of disease caused by Streptococcus pneumoniae in children younger than 5 years: global estimates. Lancet. 2009;374:893-902.

6. Safari D, Daningrat WOD, Khoeri MM, et al. Risk factors of pneumococcal carriage in children under 5 years of age in Indonesia. Presented at International Symposium on Pneumococci and Pneumococcal Diseases, April 15-19, 2018; Melbourne, Australia.

7. Rudan I, O'Brien KL, Nair H, et al. Epidemiology and etiology of childhood pneumonia in 2010: estimates of incidence, severe morbidity, mortality, underlying risk factors and causative pathogens for 192 countries. J Glob Health. 2013;3:010401.

8. Moedjito I, Alimsardjono L, Agung-Margono LS, et al. Active hospital-based epidemiological surveillance to estimate the burden of invasive pneumonoccoal disease in children aged $<5$ years in Surabaya, Indonesia. Presented at The 5th Asian Congress of Pediatric Infectious Diseases, September 23-26, 2010; Taipei, Taiwan.

9. Kartasasmita CB, Hadinegoro SR, Sudarwati S, et al. Estimating the burden of pneumonia and invasive pneumococcal disease in children under five years of age: an active hospital-based epidemiological surveillance. Presented at The 5th Asian Congress of Pediatric Infectious Diseases, September 23-26, 2010; Taipei, Taiwan.

10. Yuliarti K, Hadinegoro SR, Supriyatno B, Karuniawati A. Invasive pneumococcal disease among hospitalized children aged 28 days to 60 months in Jakarta. Southeast Asian J Trop Med Public Health. 2012;43:136-44.
11. National Institute for Health Research and Development (NIHRD) - Ministry of Health Republic of Indonesia. Indonesia: Sample Registration System 2014. 2015.

12. Rudan I, Boschi-Pinto C, Biloglav Z, Mulholland K, Campbell H. Epidemiology and etiology of childhood pneumonia. Bull World Health Organ. 2008;86:408-16.

13. Ministry of Health Republic of Indonesia. Indonesia Health Profile 2018. https://pusdatin.kemkes.go.id/ folder/view/01/structure-publikasi-data-pusat-datadan-informasi.html. Accessed December 29, 2019.

14. United Nations Children's Fund. One is too many: ending child deaths from pneumonia and diarrhoea. New York: United Nations Children's Fund; 2016. ISBN: 978-92-806-4859-1.

15. Gessner BD, Sedyaningsih ER, Griffiths UK, et al. Vaccine-preventable haemophilus influenza type B disease burden and cost-effectiveness of infant vaccination in Indonesia. Pediatr Infect Dis J. 2008;27:438-43.

16. Tan KK, Dang DA, Kim KH, et al. Burden of hospitalized childhood community-acquired pneumonia: a retrospective cross-sectional study in Vietnam, Malaysia, Indonesia and the Republic of Korea. Hum Vaccin Immunother. 2018;14:95-105.

17. McAllister DA, Liu L, Shi T, et al. Global, regional, and national estimates of pneumonia morbidity and mortality in children younger than 5 years between 2000 and 2015: a systematic analysis. Lancet Glob Health. 2019;7:e47-e57.

18. Azmi S, Aljunid SM, Maimaiti N, et al. Assessing the burden of pneumonia using administrative data from Malaysia, Indonesia, and the Philippines. Int J Infect Dis. 2016;49:87-93.

19. Hadinegoro SR, Prayitno A, Khoeri MM, et al. Nasopharyngeal carriage of Streptococcus pneumoniae in healthy children under five years old in Central Lombok Regency, Indonesia. Southeast Asian J Trop Med Public Health. 2016;47:485-93.

20. Dunne EM, Murad C, Sudigdoadi S, et al. Carriage of Streptococcus pneumoniae, Haemophilus influenzae, Moraxella catarrhalis, and Staphylococcus aureus in Indonesian children: a cross-sectional study. PLoS One. 2018;13:e0195098.

21. Kartasasmita C, Rifada M, Dewi N, et al. Pneumococcal nasopharyngeal carriage in newborns and very young infants in Indonesia, and a possible source of acquisition. Paediatr Respir Rev. 2006;7: S323-S324. 
22. Murad C, Dunne EM, Sudigdoadi S, et al. Pneumococcal carriage, density, and co-colonization dynamics: a longitudinal study in Indonesian infants. Int J Infect Dis. 2019;86:73-81.

23. Farida H, Severin JA, Gasem MH, et al. Nasopharyngeal carriage of Streptococcus pneumonia in pneumonia-prone age groups in Semarang, Java Island, Indonesia. PLoS One. 2014;9:e87431.

24. Safari D, Harimurti K, Khoeri MM, et al. Staphylococcus aureus and Streptococcus pneumoniae prevalence among elderly adults in Jakarta, Indonesia. Southeast Asian J Trop Med Public Health. 2015;46:465-71.

25. Safari D, Kurniati N, Waslia L, et al. Serotype distribution and antibiotic susceptibility of Streptococcus pneumoniae strains carried by children infected with human immunodeficiency virus. PLoS One. 2014;9:e110526.

26. MIMS. Prevenar13 Concise Info. https://www. mims.com/indonesia/drug/info/prevenar\%2013? type=full. Accessed March 14, 2019.

27. SYNFLORIX ${ }^{\circledR}$ (Pneumococcal conjugate vaccine (Non-Typeable Haemophilus influenzae (NTHi) protein $\mathrm{D}$, diphtheria or tetanus toxoid conjugates) adsorbed). Full Prescribing Information, GlaxoSmithKline, Mississauga, Ontario, 2016.

28. Pneumovax ${ }^{\circledR} 23$ (pneumococcal vaccine polyvalent). Full Prescribing Information, Merck \& Co., Inc., Whitehouse Station, NJ, 2015.

29. Prevenar 13 (pneumococcal polysaccharide conjugate vaccine (13-valent, adsorbed)). Summary of Product Characteristics, Pfizer Limited, Sandwich, Kent, 2018.

30. Synflorix (Pneumococcal polysaccharide conjugate vaccine (adsorbed)). Summary of Product Characteristics, GlaxoSmithKline Biologicals s.a., Rixensart, Belgium, 2018.

31. Soewignjo S, Gessner BD, Sutanto A, et al. Streptococcus pneumoniae nasopharyngeal carriage prevalence, serotype distribution, and resistance patterns among children on Lombok Island, Indonesia. Clin Infect Dis. 2001;32:1039-43.

32. Murad C, Dunne E, Sudigdoadi S, et al. Nasopharyngeal carriage serotype distribution and antimicrobial resistance genes of Streptococcus pneumoniae among healthy infant in Indonesia during first years of life. Presented at International Symposium on Pneumococci and Pneumococcal Diseases, April 15-19, 2018; Melbourne, Australia.

33. Harimurti K, Saldi SR, Dewiasty E, et al. Nasopharyngeal carriage of Streptococcus pneumoniae in adults infected with human immunodeficiency virus in Jakarta, Indonesia. J Infect Public Health. 2016;9:633-8.

34. Hung IF, Tantawichien T, Tsai YH, Patil S, Zotomayor R. Regional epidemiology of invasive pneumococcal disease in Asian adults: epidemiology, disease burden, serotype distribution, and antimicrobial resistance patterns and prevention. Int J Infect Dis. 2013;17:e364-e373.

35. Kim SH, Song JH, Chung DR, et al. Changing trends in antimicrobial resistance and serotypes of Streptococcus pneumoniae isolates in Asian countries: an Asian Network for Surveillance of Resistant Pathogens (ANSORP) study. Antimicrob Agents Chemother. 2012;56:1418-26.

36. Ministry of Health Republic of Indonesia, Directorate General of Disease Prevention and Control. Under-five pneumonia treatment in primary health care facility. 2018.

37. Hadi U, Duerink DO, Lestari ES, et al. Survey of antibiotic use of individuals visiting public healthcare facilities in Indonesia. Int J Infect Dis. 2008;12: $622-9$.

38. Johns Hopkins Bloomberg School of Public Health International Vaccine Access Center (IVAC). VIEWhub Report: Global Vaccine Introduction and Implementation. 2019.

39. Kumar R, Arora N, Santosham M. South Asia symposium on pneumococcal disease and the promise of vaccines-Meeting report. Vaccine. 2016;34: 2622-6.

40. Suy K, Suon K, Ly S, et al. Pneumococcal colonisation in Cambodian children one year post-PCV13 introduction. Presented at International Symposium on Pneumococci and Pneumococcal Diseases, June 26-30, 2016; Glasgow, Scotland.

41. Su LH, Kuo AJ, Chia JH, et al. Evolving pneumococcal serotypes and sequence types in relation to high antibiotic stress and conditional pneumococcal immunization. Sci Rep. 2015;5:15843.

42. Singh J, Sundaresan S, Manoharan A, Shet A. Serotype distribution and antimicrobial susceptibility pattern in children $\leq 5$ years with invasive pneumococcal disease in India-a systematic review. Vaccine. 2017;35:4501-9.

43. NHP India (National Health Portal). Universal Immunisation Programme. https://www.nhp.gov. in/universal-immunisation-programme_pg. Accessed March 25, 2019.

44. Eng P, Lim LH, Loo CM, et al. Role of pneumococcal vaccination in prevention of pneumococcal disease 
among adults in Singapore. Int J Gen Med. 2014;7: 179-91.

45. World Health Organization. Pneumococcal vaccines WHO position paper-2012. Wkly Epidemiol Rec. 2012;87:129-44.

46. Gunardi H, Kartasasmita C, Hadinegoro SRS, et al. Immunization schedule for children aged 0-18 years old. Indonesian Pediatrics Society Recommendation 2017. Sari Pediatri. 2017;18:417-22.

47. Before pneumonia, vaccinate your child. https:// edukasi.kompas.com/read/2008/04/29/18042184/ sebelum.radang.paru.segera.vaksin.si.kecil. Accessed February 25, 2019.

48. Ministry of Health, Republic of Indonesia. Plan of 3 new vaccinations to complete basic immunization. http://sehatnegeriku.kemkes.go.id/baca/rilis-media/ 20170131/3019520/rencana-pelaksanaan-3-vaksinasibaru-lengkapi-imunisasi-dasar/. Accessed October 8, 2019.

49. World Health Organization. Pneumococcal conjugate 3rd dose coverage. https://apps.who.int/ immunization_monitoring/globalsummary/ timeseries/tscoveragepcv3.html. Accessed June 22, 2020.

50. Johns Hopkins Bloomberg School of Public Health International Vaccine Access Center (IVAC). 2019 Pneumonia \& Diarrhea Progress Report Card. https:// www.jhsph.edu/ivac/resources/pdpr/. Accessed November 30, 2019.

51. Yosephine P. Indonesia National Immunization Program. Presented at International Symposium for Asia Pacific Experts, October 16-18, 2017; Hanoi, Vietnam.

52. Suwantika AA, Sitohang V, Tandy G, Herliana P, Hadinegoro SR. Cost-effectiveness and budget impact analyses of pneumococcal vaccination in Indonesia. https://immunizationeconomics.org/ baselposter/suwantika. Accessed January 28, 2020.

53. Pressing pneumonia potency in children, Bangka Belitung target as much PCV vaccine target. https:// bangka.tribunnews.com/2019/09/10/tekan-potensipneumonia-pada-anak-bangka-belitung-targetkansebanyak-banyaknya-sasaran-vaksin-pcv. Accessed January 24, 2020.

54. United Nations Children's Fund (UNICEF). One is too many: ending child deaths from pneumonia and diarrhoea. https://www.unicef.org/publications/ files/UNICEF-Pneumonia-Diarrhoea-report-2016web-version5.pdf. Accessed August 25, 2020.

55. Results for Development. Immunization financing: a resource guide for advocates, policymakers, and program managers. https://r4d.org/resources/ immunization-financing-resource-guide-advocatespolicymakers-program-managers/. Accessed $26 \mathrm{Mar}$ 2019.

56. Harjaningrum AT, Kartasasmita C, Orne-Gliemann $\mathrm{J}$, et al. A qualitative study on knowledge, perceptions, and attitudes of mothers and health care providers toward pneumococcal conjugate vaccine in Bandung, West Java, Indonesia. Vaccine. 2013;31:1516-22.

57. Blaschke AJ. Interpreting assays for the detection of Streptococcus pneumoniae. Clin Infect Dis. 2011;52(Suppl 4):S331-S337.

58. Takano C, Kuramochi Y, Seki M, et al. Molecular serotype-specific identification of Streptococcus pneumoniae using loop-mediated isothermal amplification. Sci Rep. 2019;9:19823.

59. Turner P, Turner C, Suy K, et al. Pneumococcal infection among children before introduction of 13 -valent pneumococcal conjugate vaccine, Cambodia. Emerg Infect Dis. 2015;21:2080-3.

60. von Mollendorf C, Dunne EM, La Vincente S, et al. Pneumococcal carriage in children in Ulaanbaatar, Mongolia before and one year after the introduction of the 13-valent pneumococcal conjugate vaccine. Vaccine. 2019;37:4068-75.

61. Satzke C, Dunne EM, Choummanivong M, et al. Pneumococcal carriage in vaccine-eligible children and unvaccinated infants in Lao PDR two years following the introduction of the 13-valent pneumococcal conjugate vaccine. Vaccine. 2019;37: 296-305.

62. Capeding MR, Bravo L, Santos J, et al. Prospective surveillance study of invasive pneumococcal disease among urban children in the Philippines. Pediatr Infect Dis J. 2013;32:e383-e389.

63. Capeding MR. Invasive pneumococcal serotype distribution in the Philippines [abstract 0285]. Presented at 9th International Symposium on Pneumococci and Pneumococcal Diseases, March 9-13, 2014; Hyderabad, India.

64. Haasis MA, Ceria JA, Kulpeng W, Teerawattananon $\mathrm{Y}$, Alejandria M. Do pneumococcal conjugate vaccines represent good value for money in a lowermiddle income country? A cost-utility analysis in the Philippines. PLoS One. 2015;10:e0131156.

65. Jin Y, Mankadi PM, Rigotti JI, Cha S. Cause-specific child mortality performance and contributions to all-cause child mortality, and number of child lives saved during the Millennium Development Goals era: a country-level analysis. Glob Health Action. 2018;11:1546095. 
66. Levine OS, Cherian T. Pneumococcal vaccination for Indian children. Indian Pediatr. 2007;44:491-6.

67. Farooqui H, Jit M, Heymann DL, Zodpey S. Burden of severe pneumonia, pneumococcal pneumonia and pneumonia deaths in Indian states: modelling based estimates. PLoS One. 2015;10:e0129191.

68. Nisarga R, Premalatha R, Shivananda, et al. Hospital-based surveillance of invasive pneumococcal disease and pneumonia in South Bangalore, India. Indian Pediatr. 2015;52:205-11.

69. India will now help protect over 5 million children from the life-threatening pneumococcal disease. The Hindu Business Line. May 14, 2017.

70. Lu CY, Chiang CS, Chiu CH, et al. Successful control of Streptococcus pneumoniae 19A replacement with a catch-up primary vaccination program in Taiwan. Clin Infect Dis. 2019;69:1581-7.
71. Chen $\mathrm{CH}, \mathrm{Su} \mathrm{LH}, \mathrm{Li} \mathrm{HC}$, et al. Evaluation of the impact of 13-valent pneumococcal conjugate vaccine immunization in children by surveillance of culture-confirmed pneumococcal disease: a prospective clinical microbiological study. Vaccine. 2019;37:5147-52.

72. Nakano S, Fujisawa T, Ito $\mathrm{Y}$, et al. Serotypes, antimicrobial susceptibility, and molecular epidemiology of invasive and non-invasive Streptococcus pneumoniae isolates in paediatric patients after the introduction of 13-valent conjugate vaccine in a nationwide surveillance study conducted in Japan in 2012-2014. Vaccine. 2016;34:67-76.

73. Dorji K, Phuntsho S, Pempa, et al. Towards the introduction of pneumococcal conjugate vaccines in Bhutan: a cost-utility analysis to determine the optimal policy option. Vaccine. 2018;36:1757-65. 